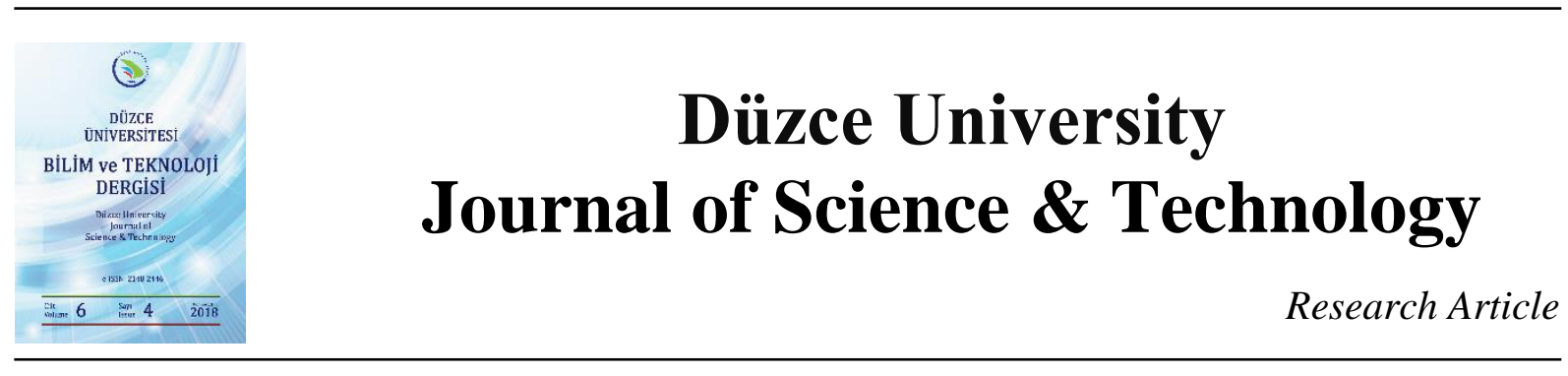

\title{
Analyzing the Effect of Voxel-Based Surface Mesh Application on Residual Stress with Simufact Additive Software
}

\author{
Ahu ÇELEBI ${ }^{\text {a, }}{ }^{,}$, Esra Zerina APPAVURAVTHER ${ }^{\mathrm{b}}$ \\ ${ }^{a}$ Metallurgy and Materials Engineering Department, Engineering Faculty, Manisa Celal Bayar University, Manisa, \\ TURKEY \\ ${ }^{b}$ Metallurgy and Materials Engineering Department, Manisa Celal Bayar University, Manisa, TURKEY \\ * Corresponding author's e-mail address: ahu.celebi@cbu.edu.tr
}

\begin{abstract}
$\underline{\text { ABSTRACT }}$
Supplementary tools are needed to perform the engineering process in additive manufacturing. Simufact Additive is a simulation tool of MSC Software that provides a solution for structural behavior during this process. Simufact Engineering and MSC Software have released a software solution to predict the most critical failure in metal AM (Additive Manufacturing) - part distortion. Analyzing provides a solution for industrial process engineers to shorten their process development time and produce high quality parts with this novel manufacturing methodology, reaching analyzing provides printing parts "right the first time". Metal powder bed fusion manufacturing faces many challenges. The main issue is occurs distortions and high residual stresses. The aim of the study analysis of effects on voxel-based surface mesh applications on bracket part used in aviation. In this study, the voxel mesh element size increases, the amount of distortion calculated on the part decreases. Increasing the element size value will reduce the working time.
\end{abstract}

Keywords: Metal Additive Manufacturing, Simufact Additive, 3D Printing, Voxel-Based Surface Mesh.

\section{Voxel Tabanlı Yüzey Mesh Uygulamasının, Simufact Additive Yazılımı ile Artık Gerilimler Üzerindeki Etkisinin İncelenmesi}

\begin{abstract}
ÖZET
Katmanlı imalat ile üretimde mühendislik sürecini yürütebilmek için destekleyici araçlar gereklidir. MSC Software'in çıkardığı Simufact Additive yazılım programı, katmanlı imalat sürecinde yapısal çözüm sağlayan bir similasyon aracıdır. Simufact Engineering ve MSC Software, Metal Katmanlı İmalattaki (M.K.İ) en kritik hatayı ve parça bozulmasını öngören bir yazılım çözümünü piyasaya sürmüştür. Amaç, endüstriyel süreç mühendisleri için proses geliştirme zamanını kısaltacak ve bu yeni imalat metodu ile yüksek kalitede parçalar üreten ve "ilk kez doğru" baskı parçalarının hedefine ulaşan bir çözüm sağlamaktır. Metal toz yatağı füzyon imalatı birçok zorluklarla karşı karşıyadır.
\end{abstract}

Received: 22/05/2018, Revised: 05/07/2018, Accepted: 23/07/2018 
Temel sorunlar distorsiyon ve yüksek kalıcı gerilmelerdir. Bu çalışmanın temel amacı, havacılıkta kullanılan destek parçasının voksel tabanlı yüzey mesh uygulamasının artık gerilmeler üzerindeki etkilerinin analiz edilmesidir. Çalışmada voksel mesh eleman boyutu değeri arttığında, parça üzerinde hesaplanan distorsiyon miktarı azalır. Eleman boyutu değerinin artması çalışma süresini azaltmıştır.

Anahtar Kelimeler: Metal Katmanlı İmalat, Simufact Additive, 3B Baskl, Voksel Tabanlı Yüzey Mesh .

\section{INTRODUCTION}

$\mathrm{N}$ owadays, industrial 3D printing is a slow and costly trial and error process. Simufact.Additive has developed an application can capture the entire process chain in the MSC's production environment and scale the simulation to the requirements of the user. The main drivers of this appliance are accuracy and speed. Simufact.Additive, allows users to quickly predict the breakdown and stress of the parts produced by metal powder bad technologies during production and at the end of the production chain. This predictive ability addresses the main points in the production of additives. The deterioration can in any case be excluded from unusable tolerances or only after a costly treatment such as the desired shape of the mill. Unwanted high residual stresses can lead to distortion of the part during production or undesired additional deterioration in the subsequent process chain, for example when cutting the part from the production base plate. This allows the user to virtually simulate and optimize factors such as setting parameters and materials, removing direction and support, creating routing, and supporting building displacement [1].

The Simufact.Additive software program uses the finite element method to accurately estimate the distortions and residual stresses on the part. The finite elements are created by the finishing element network by means of the latest, the finite element is studied. One of the most important considerations from the finite element analysis studies is whether the element size used and hence the number of elements is sufficient for that analysis. If the element network is good enough, we can say that the results of the analysis are acceptable, assuming all other inputs of the model is correct. Finite element density is an important metric used to control the accuracy of the analysis (element type and shape affect the accuracy of the analysis). Assuming there is no singularity region in the model, a high density network structure will produce results with high accuracy [2]. However, if the network of elements in the model is very busy, a large amount of computer memory and long running times will be required. This disadvantage is frequently encountered for multiple iteration conditions, especially for non-linear and transient analyzes. The main importance in this study is voxel mesh benefits compared to other mesh types. Developing model design used and no prototypes needed. The dimensions of the finishing elements used and an objects due to the variability of shapes the geometry can be fully represented. With different materials and geometric properties objects can be examined. Problems related to causal relation, general connected with the stiffness matrix generalized forces and displacements finishing elements. This feature of the method and it makes it possible to simplify. The boundary conditions can be applied easily. But there is disadvantage like modeling assumptions, difficulty of model connection designs, estimation of component interactions difficulty and damping is usually neglected. The voxel mesh is essential for it to be able to cope with the volume volumetrically and the manufacturing process will be necessary. 


\section{A. ADDITIVE MANUFACTURING AND 3D PRINTERS}

The structure and characteristics of the engineered part produced in this way are different from those produced by conventional methods (casting-plastic forming, machining, welding). The characteristics of the produced parts that all production methods; raw material (powder), production technology and process parameters [3]. Articulated production gives satisfactory-safe material properties. Produced parts can be used as final product besides prototype (model). This is called e-production, and the definition of direct metal laser sintering (DMLS) is also used. With this process, the thin layer of metal powder is melted and rapidly solidified by laser application [3].

Due to layered structure in jointed production, properties are anisotropic. Heat treatment can not completely homogenize. This is important in terms of design and requires the conditions. In articulated production, some geometry has a risk of cracking (split) and this risk is reduced by heat treatment. Surface roughness is the function of the geometry. Voltage spikes and crack propagation can occur in the interior regions [4]. This makes the specifications complicated, requiring a good surface polishing. Deformation risks can be seen especially in the lower plate and support points in joint production. The stress relieving heat treatment is the solution to this, which naturally increases the cost and prolongs the production time. Increase in surface area in dust means increase in oxygen and negative structural effect is expected. Oxygen powders below $10 \mathrm{ppm}$ (parts per million) should be preferred and the control atmosphere is also provided during production. A small number of smooth surface porosities (5-50 micrometers) can be seen in the materials surface [5].

Almost all the powder bed is metal powder fusion systems use a dust conglomeration method with a layer of powder spreading mechanism on a plate. In these systems, the building site is surrounded by a closed enclosure which is filled with an inert gas to prevent oxidation of reactive metal powders such as titanium and aluminum or under vacuum. In the middle of this cabinet is a metal dust bowl and the powder is leveled with a spreading knife. Cabinet, $700^{\circ} \mathrm{C}$ for systems using electron beam, using laser the system is preheated to a predetermined temperature depending on the process at about $100^{\circ} \mathrm{C}$ [6]. The laser or electron beam is scanned onto the metal dust surface according to the cross-sectional design of the 3D CAD paraboloid, usually 20 to $200 \mu \mathrm{m}$ thickness. Then the construction platform is lowered down to a single layer thickness, this process is repeated until the new dusty grain and part are completed on the dusting knife part [6-7].

\section{B. SIMUFACT SOFTWARE AND SIMUFACT ADDITIVE}

Simufact Additive is a process solution for getting the process right for the first time. Distortion of parts during the printing and production process constitutes a major obstacle to the corporations, which does not see all the benefits of the additional production process. Too much inefficient time and currency spent on trial and error. Simufact Additive is a solution aimed at predicting and solving the impairment during the entire printing, heat treatment, cutting and HIP process before sending a piece to the machine. Simufact Additive has been developed for the simulation of Powder Bed Fusion Additive Manufacturing. Simufact Additive; Production methods such as Selective Laser Melting (SLM), Direct Metal Laser Sintering (DMLS) (EOS), LaserCUSING ${ }^{\circledR}$ (Concept Laser) and Electron Beam Melting (EBM) can be analyzed. Simufact Additive, the joint production process; All steps such as jointed production, cutting of support 
elements, heat treatment / stress relief and hot isostatic pressing (HIP) can be examined. With jointed production simulations: The distortions and residual stresses on the part can be calculated by the end of the analysis. The residual stresses can be reduced most of the optimum parts orientation that can be determined and the support elements optimized [8-12].

In the vocabulary, voxel represents a value on a regular grid in three-dimensional space. Voxel mesh refers to the volumetric mesh structure. The solution is provided by separating the mesh pieces into 3 dimensions. We get a definite conclusion about the entire cistern compared to the other mesh tours as the objects in this mesh are provided in 3D. The surface is laid after the surface mesh, the voxel mesh and is complementary to each other. For an example in Figure 1.a, a manifold part is roughly simulated in Simufact.additive program. A manifold part is a wide and bigger pipe, or channel, into which smaller pipes or channels lead. It can be supplied in one piece production-level production, and it can be simulated on this shelf. It's hard to manufacture it one piece, but with additive manufacturing it is possible. As you can see in the figures the color scale under the effective stress of the simulated part is the same as in Figure 1.b. The color scale shows the parts in the simulated section that have the maximum and minimum values of the effective stress values. The amount of effective stretching in the red zone is greater. Blue is the least in the regions, yellow and green are the middle in the regions. In Figure 1.c, there are distortions of the manifold part. The distortions usually concentrate on the parts and the connections (shown in red color). The external parts are less in the blue, yellow and green regions. The aim of the work within this information is to reduce the distortion results by changing the voxel meshes element size of the bracket part used in aviation reaching a conclusion by reducing distortions.
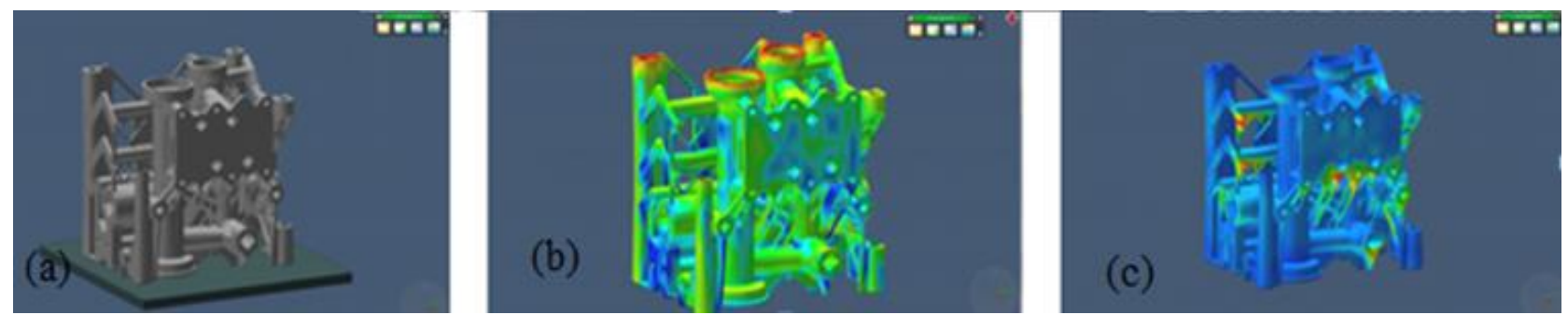

Figure 1. a) Sample of Manifold part. b) Sample of Manifold part - effective stress. ) Sample of Manifold partdistortions.

\section{MATERIAL AND METHOD}

In this study bracket part will be used shown in Figure 2.a. The "bracket" part utilized in aviation field was used in the experiment. The experimental process of Simufact.Additive, includes mostly in eight steps (Figure 3). In the first step bracket part is imported. It can be a CAD drawing or technical drawing from other programs (Figure 2.b.). 


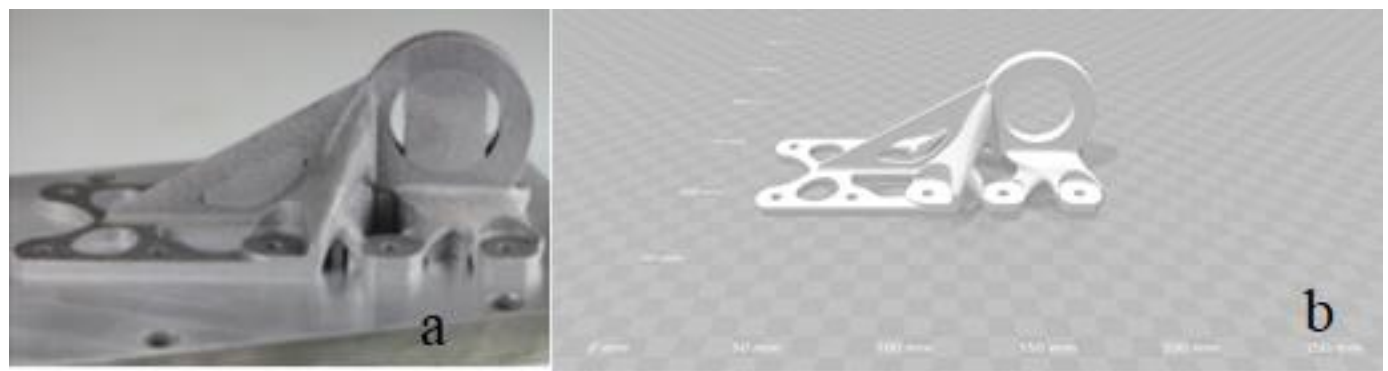

Figure 2. a) Original bracket part. b) Technical drawing of bracket part [9].

Second step is generating supports or importing for additive manufacturing bracket part. We can assign "ten" support structures to the part and thus demonstrate that the Simufact.Additive simulation program can be applied to complex parts such as aerospace brackets. Support radius is $0.370005 \mathrm{~mm}$. In the third step the user will define the manufacturing parameters shown in below. Part section in the build space dimensions in $\mathrm{X}, \mathrm{Y}$ and $\mathrm{Z}$ direction is $250 \mathrm{~mm}$. Bounding box minimum coordinates in $\mathrm{X}$ direction is 38.7459 , in $\mathrm{Y}$ direction 87.5 and in $Z$ direction is 2.16043 . Distance to left centering is $44.5925 \mathrm{~mm}$, distance to front centering is $92.5 \mathrm{~mm}$ and distance to bottom is $2.16043 \mathrm{~mm}$. Positioning-manual positioning moved by $\mathrm{Z}$ direction is $5.00 \mathrm{~mm}$. Automatic centering of part $\mathrm{Z}$ offset from base plate is $15.00 \mathrm{~mm}$. Critical surface angle is 45. The selected machine will be EOS M20 for use in the experiment. Material selected in this experimental process is TiAl6V4 metal powder. More detailed information about Ti6Al4V metal powder is shown in Table 1.

Table 1. Metal powder properties of Ti6Al4V.

\begin{tabular}{cc}
\hline Density & $4,41 \mathrm{~g} / \mathrm{cm}^{3}$ \\
\hline Minimum wall thickness & $0,3-0,4 \mathrm{~mm}(\mathrm{millimeter})$ \\
\hline Maximum particle size & $\mathrm{d} 50$ (DIN ISO 13320) \\
\hline Layer tickness & $30 \mu \mathrm{m}$ (micrometer) \\
\hline Material composition & $\mathrm{Al}(5.5-6.5 \%)$ \\
& $\mathrm{V}(3.5-4.5 \%)$ \\
& $\mathrm{O}<2000 \mathrm{ppm}(\mathrm{parts}$ per million $)$ \\
$\mathrm{N}<500 \mathrm{ppm}$ \\
$\mathrm{C}<800 \mathrm{ppm}$ \\
$\mathrm{H}<120 \mathrm{ppm}$ \\
\\
Fe $<2500 \mathrm{ppm}$ \\
\end{tabular}

Simple cutting in properties $-X$ (right to left) height $=3.0 \mathrm{~mm}$. Vertex angle $=1.74533$ radius, edge angle $=1.0472$ radius and curvature divisions $=12 \mathrm{~mm}$. The parameters used in this study remain the user's preference. The only parameter that is significant in the beginning of the operation is the voxel-based surface mesh. Fourth step is the articles main topic, voxel and surface mesh created. Surface mesh in every analysis is $2.0 \mathrm{~mm}$. Advanced surface meshing parameters $\mathrm{min}=0.4 \mathrm{~mm}$. Surface mesh is the type of mesh that is transferred to the bracket part after the voxel mesh. Voxel mesh values were analyzed with 5 analysis average in relation to the actual experimental studies performed. The dimensions of the element size of voxel mesh are $0,50 \mathrm{~mm}, 0,75 \mathrm{~mm}, 1,00 \mathrm{~mm}, 1,85 \mathrm{~mm}$ and $2,50 \mathrm{~mm}$. There is no difference between $0.75 \mathrm{~mm}$ element size and $1,00 \mathrm{~mm}$ element size. $0,75 \mathrm{~mm}$ element size is about 25 minutes to finish the experiment. 
$1,00 \mathrm{~mm}$ element size is 28 minutes to integrate the experimental process. The voxel mesh will directly analyze the distortions. The main reason for this is to decompose the particle volumetrically, that is to obtain a net semblance after it has acquired the structure of the network then coarsely disappears. The voxel and surface mesh can't be compared to each other they are complement. Fifth step in intermediate analysis result shown is unaccomplished. It shows that the experimental process will be complete. Sixth step the user finally can get the results after the manufacturing process. After getting the results, the user must remove the plate under the bracket part (as usual in additive manufacturing). The last step is removing supports which will be imported by the user in Step 2.

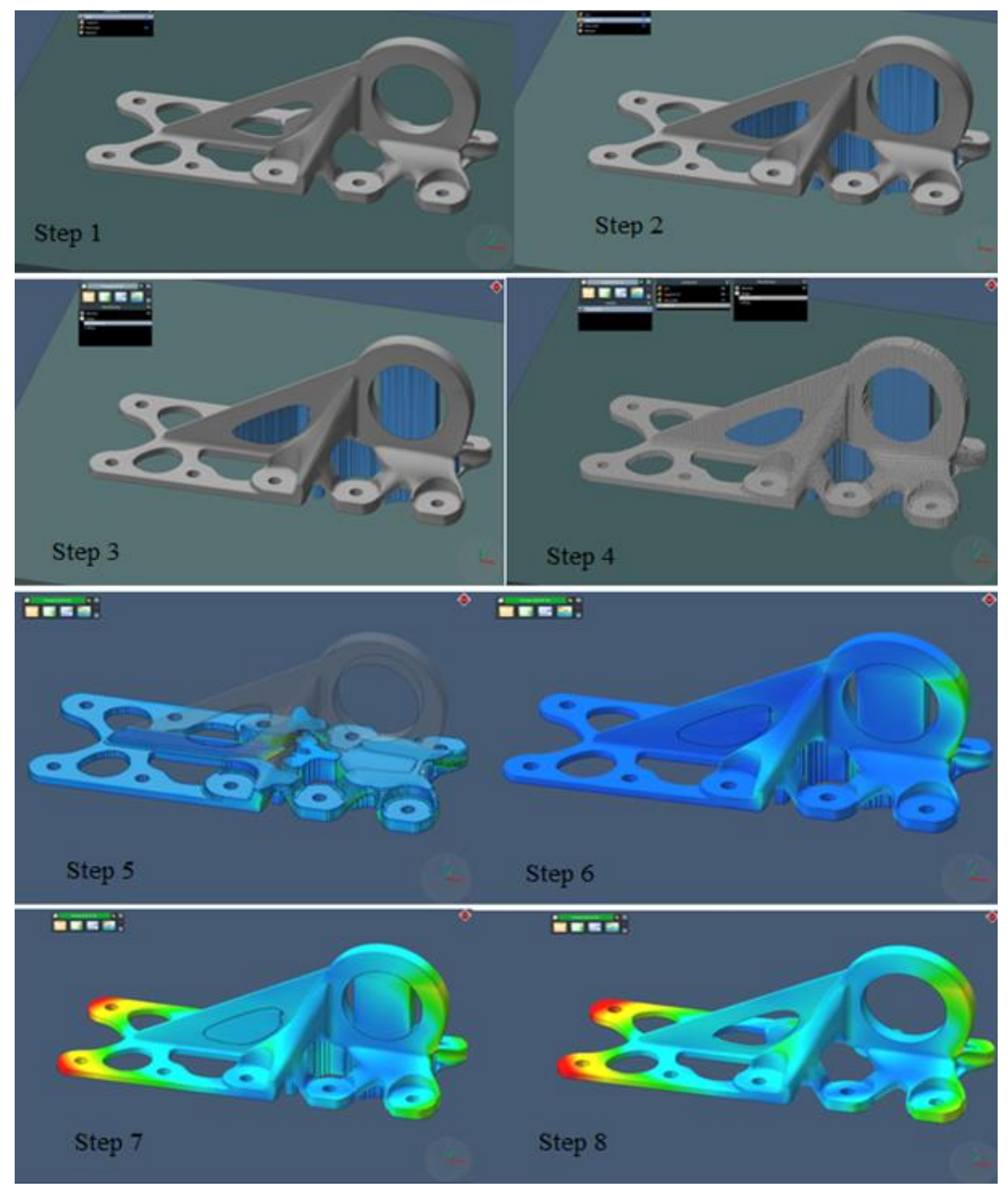

Figure 3. The experimental process of Simufact.Additive in eight steps.

\section{RESULTS AND DISCUSSION}

The aim of using Simufact.Additive software program in metal additive manufacturing is to save time and cost. We can see the difference between analytical and numerical values by simulating a specimen once on 
this numerical and then producing it with layered manufacturing. Computer aided engineering (CAE) and Simufact Engineering is the most powerful tools recently used to provide cost-effective results. It takes time and expense to do physical experiments for each design revision. Design engineers can instead do numeric work to reduce the number of prototypes. This saves considerable effort, money and time. However, no matter how good the performance of the simulation software is, it is unlikely that the numerical analysis will provide $100 \%$ accuracy. Mesh generation can be defined as a process of dividing a physical description range into smaller definition ranges (elements). The aim here is to facilitate the solution of a differential equation. The correctness of the approximation of the results obtained by the finite element method due to the finite element depends on the element type and number of elements used in the network.

The main problem with additive manufacturing (3D Printing Technologies) is distortion and residual stresses. The aim of our experimental process is to reduce the distortion. Includes rough sketch analysis slides; the necessary data is entered (as in the case of the experimental process) support created or can be imported. Define manufacturing parameters. It is produced with additive manufacturing together with support elements. Mesh must be created at this time. The voxel mesh is thrown in order to obtain a value as close as possible to the network structure. After the volumetric mesh is finish in that duty, a payout is obtained from there. This output will be the basis for the surface mesh, which is complementary to each other. When the surface mesh is complete, the analysis is finished the results are receivable of manufacturing. The last point is after getting the results, must do plate removal. In this study it has been done $-X$ (right to left) position after removable the supports must be removal too. These values are entirely personal and the values close to the actual values that are chosen.

End of the process, the residual stresses that can be made by transferring the distortions to the part in a negative way (an approach similar to the transfer of the back spring to the mold in negative form) Simufact.Additive analyzes mainly on distortion and element sizes. The noble intension is to find out where the experimental process goes as the element size decreases (Figure 4). The graphic shows the voxel meshes element size increases, calculated distortion on the bracket will decreases. If the element size increases the time will decreases. There is an inverse relationship between element size of voxel mesh and time. The first analyzes voxel meshes element size is $0.50 \mathrm{~mm}$, the time is about 100 minutes ( 1 hour and 40 minutes). The second experiment is $0,75 \mathrm{~mm}$ and it takes about 25 minutes. The third experimental process is $0,75 \mathrm{~mm}$ which is same as second process and took about 28 minutes. In this study we didn't add the second experimental process because it has no difference between the third processes. They are similar for the simulation programs. The fourth experimental process is $1,85 \mathrm{~mm}$ of voxel mesh element size is only 4 minutes. The last and the fifth experimental process continue as $2,50 \mathrm{~mm}$ element size of voxel mesh and time is around 1.5 minutes. In this case the users can commentary as calculated distortions amount for better mechanical properties which can be used in the aerospace bracket part. 


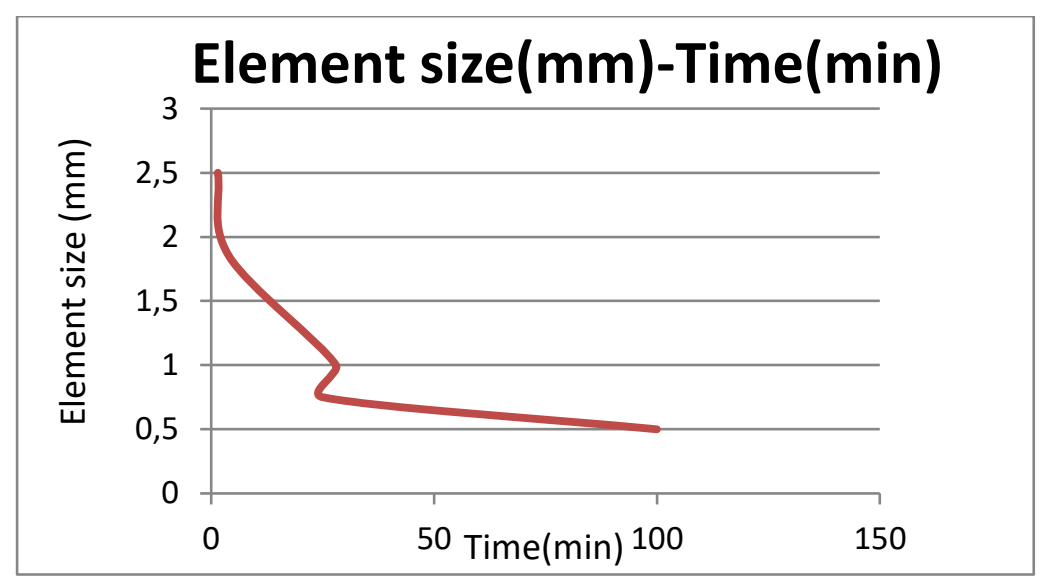

Figure 4. Element size- time graphic.

Table 2 shows that are completed in the experimental processes. First analysis element size of voxel mesh is $0.50 \mathrm{~mm}$ time is about 1 hour and 40 minutes (Figure 5.a.). In Figure 5.b shows deformation term in maximum $=0.92$ and minimum $=-0.99$. The residual stress in first analysis maximum value is $1319.80 \mathrm{MPa}$ and it is the highest in all experimental processes. The second experiment in Figure 5.c is element size of voxel mesh $1.00 \mathrm{~mm}$ is completed in 28 minutes. In Figure 5.d shows deformation term in maximum=0.93 and minimum $=-0.99$ same as the deformation term in first analysis. The residual stress in second analysis maximum value is $1302.46 \mathrm{MPa}$. Third analyzes element size of voxel mesh is $1,85 \mathrm{~mm}$ and took around 4 minutes (Figure 5.e.). In Figure 5.f shows deformation term in maximum $=0.80$ and minimum $=-0.86$. The residual stress in third analysis maximum value is $1298.78 \mathrm{MPa}$. The latest analysis results are element size of voxel mesh is $2,50 \mathrm{~mm}$ and takes short time 1,5minutes only (Figure 5.g.). In Figure 5.h shows deformation term in maximum $=0.78$ and minimum $=-0.83$. The residual stress in latest analysis maximum value is $1223.79 \mathrm{MPa}$. In all the experimental process the minimum residual stresses are 0MPa.

Table 2. Comparison of experimental processes analyzes list.

\begin{tabular}{lcccccc}
\hline Analyzes & $\begin{array}{c}\text { Residual } \\
\text { Stress } \\
\text { Max } \\
(\mathrm{MPa})\end{array}$ & $\begin{array}{c}\text { Residual } \\
\text { Stress } \\
\text { Min } \\
(\mathrm{MPa})\end{array}$ & $\begin{array}{c}\text { Deformation } \\
\text { Term } \\
\text { Max } \\
(\mathrm{mm})\end{array}$ & $\begin{array}{c}\text { Deformation } \\
\text { Term } \\
\text { Min } \\
(\mathrm{mm})\end{array}$ & $\begin{array}{c}\text { Element } \\
\text { size } \\
(\mathrm{mm})\end{array}$ & $\begin{array}{c}\text { Time } \\
\text { (minutes })\end{array}$ \\
\hline 1. Analysis & 1319,80 & 0 & 0,92 & $-0,99$ & 0,50 & $\begin{array}{c}100(1 \\
\text { hour } 40 \\
\text { minutes })\end{array}$ \\
\hline 2. Analysis & 1302,46 & 0 & 0,93 & $-0,99$ & 1,00 & 28 \\
\hline 3. Analysis & 1298,78 & 0 & 0,80 & $-0,86$ & 1,85 & 4 \\
\hline 4. Analysis & 1223,79 & 0 & 0,78 & $-0,83$ & 2,50 & 1,5 \\
\hline
\end{tabular}

The element size of voxel mesh is reduced, it causes more geometric deviation. More precise solutions can be achieved by reducing the element size. But here the "best-fit" method makes it clear that the real parts and the simulated parts are clearly visible. The underlying cause is that the more sensitive solution causes more deformation term. If the voxel mesh has element size as small as the value, the experiments time will increases. The reduction of the voxel mesh value will provide a more detailed solution. It can converge with the actual resultant values. 
The calculated values of the distortion values obtained by the analysis are calculated by making "best fit" on the original part. Users can compare simulation results and reference model by the "best-fit" positioning accuracy. In the best-fit method, the software automatically determines the position at which the deviations are lowest. Once this is done, the software automatically calculates the deviation of the manufactured part to the initial part - based on a "best fit method". This process is repeated several times. The best fit points are taken casually. After 3-5 iteration steps, the user receives a geometry that shows minimum deviations to the initial part. Simulations with multiple or complex parts are possible as well but naturally will need more time. This new feature is essential since virtual distortion compensation replaces time consuming and costly try-outs. The visual presentation of the results, based on measurements, allows the user to quickly assess whether the deviations are within the permissible tolerances.

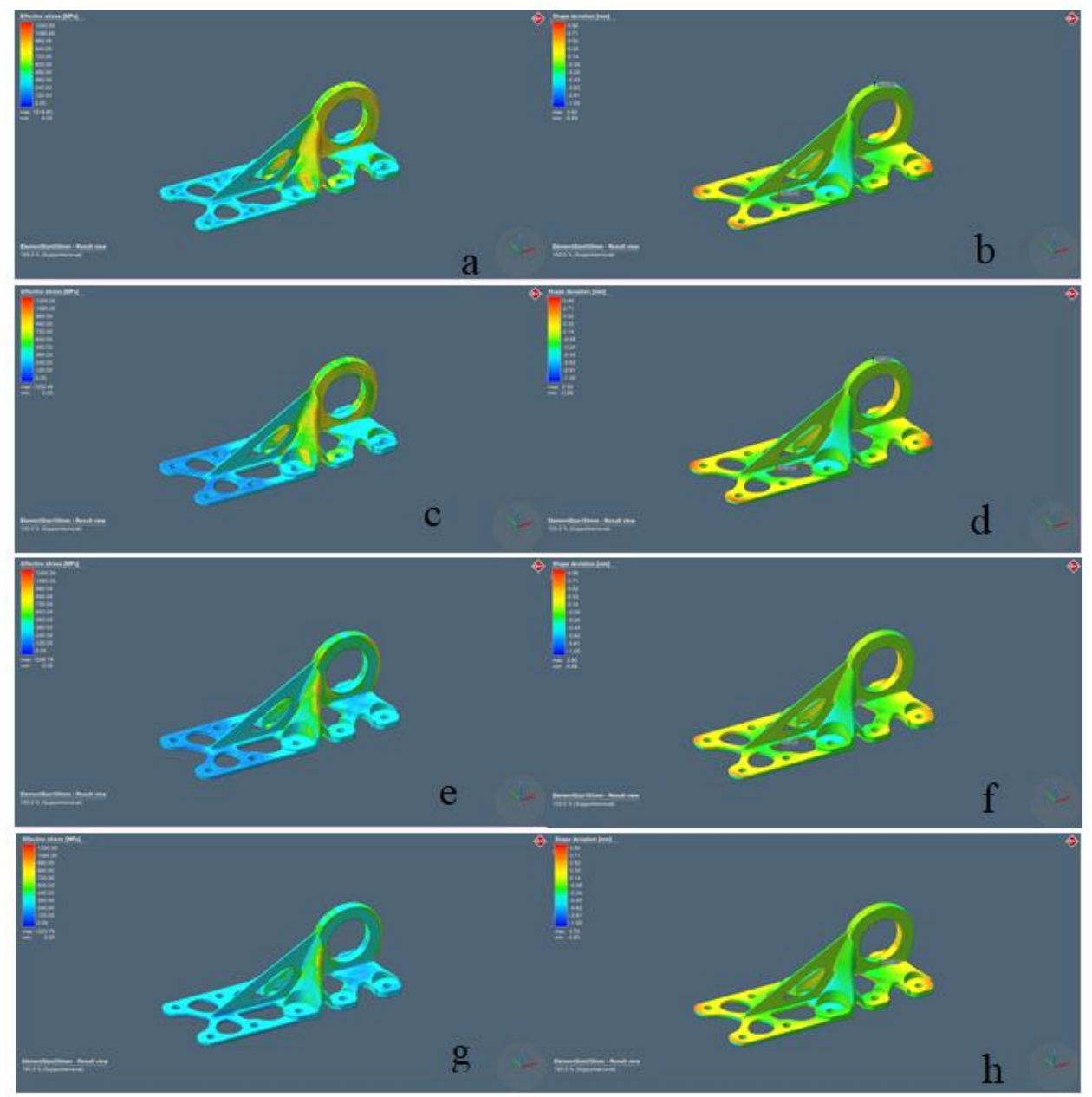

Figure 5. a) Effective stress values of element size $0.75 \mathrm{~mm}$. b) Deformation Term of element size 0.75 mm.c) Effective stress values of element size $1.00 \mathrm{~mm} . \boldsymbol{d})$ Deformation Term of element size $1.00 \mathrm{~mm} . \boldsymbol{e}$ ) Effective stress values of element size $1.85 \mathrm{~mm}$. $\mathrm{f}$ ) Deformation Term of element size $1.85 \mathrm{~mm} . \mathrm{g}$ ) Effective stress values of element size $2.50 \mathrm{~mm}$. h) Deformation Term of element size $2.50 \mathrm{~mm}$. 


\section{CONCLUSION}

As can be seen in the numeral analyzes, the different element types and dimensions affect the results of the analysis. The finite element method is a metric that produces approximate solutions. The solution can be repeated by increasing the number of elements, changing the element type, changing the mesh production method, or manually playing on the mesh. Thus, the difference between the results can be observed. Many applications use a bottom-up approach to mesh production. In this approach, the points are first mesh and then the curves, volumes and finally the surfaces are meshed. In this embodiment, the next mesh generation operation is based on the previous mesh generation operation as input. One of the most important considerations from the finite element analysis studies is whether the element size used and hence the number of elements is sufficient for that analysis. If the element network is good enough, we can say that the results of the analysis are acceptable, assuming all other inputs of the model is correct. Finite element density is an important metric used to control the accuracy of the analysis (element type and shape affect the accuracy of the analysis). Assuming there is no singularity region in the model, a high density network structure will produce results with high accuracy. However, if the network of elements in the model is very busy, a large amount of computer memory and long running times will be required. This disadvantage is frequently encountered for multiple iteration conditions, especially for non-linear and transient analyzes.

Simultaneous 3D design and component analysis through 3D simulation will reach a greater scope and precision in the coming years, while the need for in-service predictability is at its peak. The tools used for engineering, simulation, production preparation and production with 3D printers are grouped together in a single connected system, which removes the risk of losing the possibility of error-prone data conversion and the information content associated. Generally very close results can be obtained in the simulation programs. Simufact.Additive will provide faster and more accurate as much as possible results with the addition of new features in the first and later versions of this field. Simulation tools will supply and provide ease of production methods. The important thing is to be able to provide the necessary support to a new production method. By using this program which is used by the big companies in the world, which is preferred by the big companies in the Middle Europe, it is possible to increase the added value and provide more support to the digital industry fields by using this simulation program with the progressive versions. This study has been done to raise awareness about this issue.

The final analysis shows that the voxel mesh is modified and the surface mesh is kept constant so that the increase in element size will reduce the amount of distortion for each calculated analysis. Time parameter will decrease with element sizes increase. But this will provide a rougher result than the other solutions that has been done in this study.

ACKNOWLEDGEMENTS: Many thanks and regards to Process Manager Mr. Mert AYGEN and NETFORM Engineering Machinery Metal Co. for giving a one-month license of Simufact.Additive simulation program for our study. 


\section{REFERENCES}

[1] MSC Additive Manufacturing, Computer Program, Simufact Volume VII, California, 2017.

[2] L. S. Bertol, W. K. Júnior, F. P. Silva, and C.Aumund-Kopp, "Medical design: Direct Metal Laser Sintering of Ti-6Al-4V" Materials and Design, vol. 31, pp. 3982-3988, 2010.

[3] C. K. Chua and K. F. Leong, Rapid Prototyping: Principles and Applications in Manufacturing, Wiley, New York, 1998.

[4] C. Brancher, "Materials Solutions 3D Printing/DMLS Expectation to Enlightenment", EOS IUM, 2013.

[5] J. P. Kruth, M. C. Leu and T. Nakagawa, "Progress in Additive Manufacturing and Rapid Prototyping", Ann CIRP, vol. 47, no. 2, pp. 525-540, 1998.

[6] A. Masmoudi, R. Bolot and T. Coddet, "Investigation of the Laser-Powder-Atmosphere Interaction Zone During the Selective Laser Melting Process”, J. Mater. Process. Technol, vol. 225, pp. 122-132, 2015.

[7] M. J. Matthews, G. Guss, S.A. Khairallah, A.M. Rubenchik, P.J. Depond and W.F..E. King, "Denudation of metal powder layers in laser powder bed fusion processes", Acta Mater, vol. 114, pp. 3342, 2016.

[8] Netform Metal, Simufact.Additive, (2018, February 2), [Online]. Available: http://www.netformmetal.com/en/simufact_additive.asp 2 February 2018

[9] MSC Software Company, (2018, February 1), [Online]. Available: https://www.simufact.com/simufact-additive.html 1 February 2018

[10] M. Matthias and C. Körner. "Powder layer deposition algorithm for additive manufacturing simulations." Powder Technology, vol.300, pp. 125-136, 2018.

[11] Hwang, I. H., P. Mehmet, and Michael Tran. "Metal Additive Manufacturing Process Simulation for the Hinge of the Engine Hood." Kore Hassas Mühendislik Derneği, Kore, 2017, pp. 162-162.

[12] L. Julian, et al. "Simufact Additive 1.0-a new era in simulating 3D-printing processes." Kore Hassas Mühendislik Derneği, Kore, 2017, pp. 262-262. 